\title{
СПОРТИВНАЯ ПСИХОФИЗИОЛОГИЯ КАК НОВОЕ НАПРАВЛЕНИЕ ПСИХОЛОГИИ
}
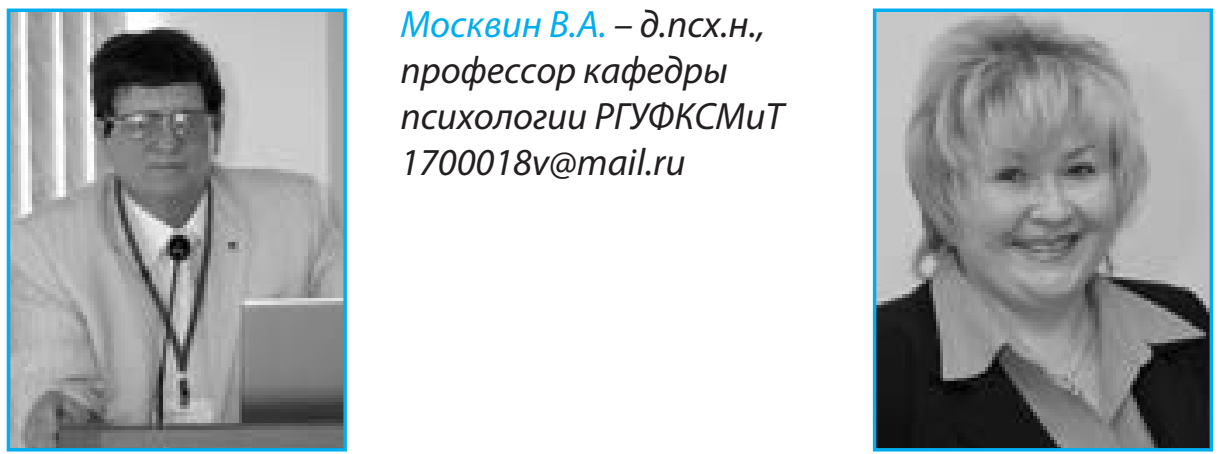

Москвина Н.B. - к.nсх.н., дочент кафедры психологии РГУФКСМит

Ключевые слова: индивидуальные различия, волевая регулячия, мозг, асимметрии, латеральные профили, спорт высших достижений.

Keywords: individual differences, volitional regulation, brain, asymmetry, profiles laterality, sports of highest achievements.

Резюме. Проанализировано значение исследований индивидуальных особенностей функциональных асимметрий человека для решения проблем спорта высших достижений. Рассмотрена проблема парциального доминирования в ре-ализации двигательной одаренности спортсменов, а также проблема леворукости в спортивной психологии. Исследованы признаки доминирования левых лобных отделов у студентов спортивного вуза в возрасте 17-20 лет $(n=46)$. Результаты показывают значимость доминирования структур левого полушария в реализации волевых возможностей человека. Обосновывается и констатируется развитие нового направления психологии - спортивной психофизиологии.

Введение. Сегодня в психологии успешно реализуется такое новое направление, как психофизиологический подход к проблеме индивидуальных различий [2-4]. Исследования последних лет свидетельствуют о развитии нового направления, которое можно обозначить как психофизиологический подход к проблеме индивидуальных различий с учетом особенностей индивидуальных функциональных асимметрий человека [2-10, 12-15].

Концепция А.Р. Лурия [1] о парциальном доминировании зон мозга позволяет говорить о том, что основы индивидуальных различий здоровых людей связаны с вариабельностью сочетаний парциального доминирования сенсорных и моторных признаков (что определяет разный их вклад в процессы реализации высших психических функций).
Summary. Analyzed the importance of research of specific features of functional asymmetries person to solve the problems of high performance sport. The problem of partial dominance in the implementation of motor gifted athletes, but also the problem of left-handedness in sports psychology. Abstract signs of dominance of the left frontal areas of the sports university students aged 17-20 years $(n=46)$. The results show the importance of the structures of dominance of the left hemisphere in the implementation of volitional human capabilities. Substantiates and stated the development of a new direction of psychology - sports psychophysiology.

Для изучения особенностей функциональных асимметрий человека в настоящее время широко используются методики А.Р. Лурия, направленные на оценку «парциального левшества» (или парциального доминирования определенных зон мозга), а также пробы других авторов, включенных в «Карту латеральных признаков» [2-4] .

A.P. Лурия, касаясь проблемы способностей и одаренности в целом, говорил о наличии «плюс-симптомов» и «минус-симптомов» в функционировании психики. «Плюссимптомы», например, в виде парциального доминирования зрительных $30 \mathrm{H}$ правого полушария обеспечивают более быструю переработку зрительно-пространственной информации (с учетом специализации правого полушария для реализации данной функ- 
ции). «Плюс-симптомы» в виде парциального доминирования височных (слуховых) зон правого полушария обеспечивают более быструю переработку музыкальной информации (мелодия, звуки), а при парциальном доминировании височных зон левого полушария происходит более каче-ственная переработка слухо-речевой информации. Т. о, парциальное доминирование определенных зон мозга усиливает соответствующие функции (в том числе, и в сфере двигательной активности), что имеет самое прямое отношение к проблеме одаренности в спорте [2-5].

В психофизиологии индивидуальных различий особое значение имеет исследование N.Sakano, который валидизировал критерии определения «парциального левшества» А.Р.Лурия на больших контингентах японской и немецкой популяций (свыше 2 тыс.) и показал, что асимметрия пробы "перекрест рук" (по данным ЭЭГ) связана в значительной степени с функциями лобных долей и отражает их относительное доминирование [16]. Этот факт обращает на себя внимание новым подходом к диагностическому значению пробы "перекрест рук" и дает возможность по-новому оценить исследования прежних лет, в частности, работы В.Д. Небылицына [11], считавшего лобные доли нейрофизиологическим субстратом "лобно-ретикулярного" и "лобно-лимбического" комплексов мозга. По В.Д. Небылицыну, левая и правая лобные доли находятся в реципрокных взаимоотношениях и определяют два основных параметра индивидуальности - "общую активность" и "эмоциональность".

Учет особенностей функциональных асимметрий мозга (ФАМ) в спортивной деятельности имеет значение в плане выявления одаренности в определенных сферах психики (например,в двигательной сфере), что связано с парциальным доминированием лобных (двигательных) отделов мозга, в особенности его левой лобной доли. Воспитание спортсменов высокого класса часто ведется на уровне предельных физических и психических напряжений, что определяет углубление научных представлений о физиологических механизмах совершенствования функциональных резервов человеческого организма в процессе адаптации к возрастающим нагрузкам и требует обязательного учета индивидуальных особенностей спортсмена (в т.Ч., и латеральных).

Из спортивной психологии нам известно, что попытки обучать юных спортсменов посредством усиления и тренировок неведущего органа (руки, ноги), т.е. без учета индивидуальных особенностей асимметрий, может приводить к отрицательным результатам в виде задержек развития при формировании спортивного мастерства. Проблема леворукости имеет большое значение и в спортивной практике. Левый профиль асимметрии у борцов, боксеров, теннисистов, фехтовальщиков делает их крайне неудобными соперниками для чистых правшей. Во многих исследования затрагиваются проблемы переучивания левшей, в том числе в процессе физического воспитания или обучения технике и тактике в разных видах спорта. Показано, что обучение юных футболистов-левшей техническим приемам через неведущую (правую) ногу замедляет физическое развитие. Поэтому учет левых моторных асимметрий у леворуких спортсменов и правильное их развитие способствует более высоким спортивным достижениям, правильному выбору амплуа и тактики действий спортсмена. Обучения юных спортсменов с учетом их индивидуальных латеральных профилей являются одной из центральных задач применения знаний нейропедагогики в спорте. Психофизиологическая диагностика индивидуальных особенностей (в т.ч. и двигательных способностей) может быть использована для тестирования и выявления двигательно одаренных детей и подростков к определенным видам спорта [4-5].

В настоящее время психологами проведен ряд исследований по разработке теории самоорганизации, в которых изучается динамика систем, самоорганизующихся через параметры порядка. В качестве последних в психологии могут рассматривать такие психологические характеристики как «временная перспектива», «целеобразование», «полезависимость - поленезависимость», «антиципация». Эти параметры имеют самое непосредственное отношение и к спорту [2; 4-5].

Временная перспектива очерчивает ту область отражения человеком мира, которая связана с восприятием, осознанием времени как пространства развития и самореализации. Временная перспектива - это, прежде всего, будущая возможность реализации или «нереализации» человеком своих замыслов. При этом будущее соотносится с возможностями, представляющими собой потенциал дальнейшего развития. К. Левин считал, что жизненное пространство человека не ограничивается только актуальной ситуацией, оно 
включает в себя не только настоящее, но также прошлое и будущее. Уровень развития будущей временной перспективы, ее продолжительность и оптимистичность связаны с уровнем психического и социального развития личности. Позитивная временная перспектива, создаваемая достойными целями - это один из основных элементов высокой морали. В то же время это и реципрокный процесс: высокая мораль сама создает длительную временную перспективу и устанавливает достойные цели.

По А.Н. Леонтьеву (1977) цели отводиться системообразующая роль в построении деятельности. «Целеобразование выступает в качестве важнейшего момента движения той или иной деятельности субъекта», целеполагание (целеобразование) - «субъективное выделение цели, т.е. осознание ближайшего результата, достижение которого осуществляет данную деятельность. По О.К. Тихомирову (1984) в основе образования цели лежит отражение развития предметного содержания деятельности. Для деятельности более простого уровня организации, ориентированной на реализацию возможностей наличной ситуации, характерна постановка конкретных целей. Для деятельности более высокого уровня, ориентированной на предварительное преобразование исходной ситуации, преобладают общие цели. Что касается самого высокого уровня деятельности, ориентированного на единый процесс, включающий и предварительное преобразование исходной ситуации, и его последующую реализацию, то здесь имеет место образование целевых структур, включающих и общие и конкретные цели. Возникновение этих целей тесно связано с функционированием таких механизмов, как оценка возможностей, так и перспектив преобразования данной ситуации [2; 4-5].

Антиципационные процессы выступают в роли ведущего звена механизма психической регуляции поведения в деятельности. Именно антиципация обеспе-чивает формирование цели, планирование и прогнозирование поведения в дея-тельности, она включается в процессы принятия решения, текущего контроля и коммуникационные акты. Антиципация пронизывает все уровни отражения действительности. Она возникает как системно интегральный процесс, формирующийся в реальной деятельности человека, и является одним из важнейших компонентов механизма регуляции этой деятельности (в том числе и поведения в целом). Уровень развития анти- ципации свидетельствует об уровне развития психики в целом.

Индивидуальные стилевые особенности деятельности и познания являют-ся не менее существенными, чем характеристики ее результативности. Полезависимость поленезависимость обнаруживают всепроникающий характер влияния на деятельность и поведение личности. Поленезависимость оказалась отрицательно связанной со шкалой эмоциональности и положительно - со шкалой социальной эргичности и социальной пластичности. Очевидно, высокая потребность в освоении социальной сферы деятельности, широкий набор коммуникативных программ и незначительная потребность в одобрении своих поступков со стороны окружающих, отражают стремление поленезависимых индивидов к последовательному соблюдению принятой ими стратегии межличностного поведения, желание по-своему структурировать те социальные ситуации, в которых им приходиться действовать. Полезависимость - поленезависимость выводит нас на универсальную дихотомию «ориентация на других людей - ориентация на дело».

Данные психологические характеристики могут рассматриваться также с учетом особенностей функциональных асимметрий и индивидуальных профи-лей латеральности. В последние годы в психологии был выполнен целый ряд работ, направленный на поиск связи признаков и показателей асимметрии че-ловека с его индивидуальными характеристиками. Одним из направлений в изучении индивидуальных когнитивных стилей является изучение связи полезависимости поленезависимости индивидов от типов межполушарной асимметрии мозга. Накопление правосторонних признаков латеральности (что отражает относительное доминирование левополушарных структур мозга) считается предпосылкой для проявления поленезависимого когнитивного стиля. Наиболее благоприятным с этой точки зрения является тип ППП (в системе измерений «рука-ухо-глаз»), т.е. унилатеральные праворукие. Накопление правосторонних признаков в типах межполушарной организации мозга коррелирует с большей полезависимостью испытуемых.

Методика. Проведенное нами исследование было направлено на выявление различий в уровне сформированности регулятивных и целеобразующих функций у студентов спортивного университета (17-20 лет, $\mathrm{n}=46)$. 
Экспериментальная группа была представлена праворукими юношами и девушками, которые составили 92 \% от общего количества обследованных (левши составили около 8 \% - 4 человека). Выборка была разделена на две подгруппы по показателю пробы «перекрест рук»: испытуемые с правым показателем - 23 человека (16 девушек и 7 юношей); испытуемые с левым показателем - 23 человека (12 девушек и 11 юношей). Использовались такие методики как, «Карта латеральных признаков» (с учетом показателей пробы «перекрест рук»), опросник 16-ФЛО Р. Кеттела, методика УСК, а также интерпретационные коэффициенты теста Люшера. Для статобработки исполь-зовалась программа "STADIA".

Результаты исследования. Были обнаружены корреляции между показате-лями пробы «перекрест рук» и некоторыми шкалами опросника Кеттела, об-щим уровнем интернальности в методике УСК, а также с интерпретационными коэффициентами теста Люшера. Выявлена связь между полом и некоторыми шкалами опросника Кеттела и показателем общей интернальности (методика УСК).

Результаты согласуются с данными, в которых были обнаружены более высокие показатели выполнения интеллектуальных проб (матриц Равена и фактора «В» опросника Кеттела). Это объясняется наличием более высокого уровня динамических характеристик мыслительной деятельности у испытуе-мыхмужчин, имеющих правый показатель пробы "перекрест рук" [2]. На основе полученных данных можно сделать вывод, что мужчины с правым показателем в пробе "перекрест рук", что отражает доминирование левой лобной доли по N.Sakano [16] более рациональны, автономны и независимы, а также более устойчивы в выбранных программах поведения. Для индивидов с левым показателем пробы «перекрест рук» характерны более низкие показатели по ряду шкал, что свидетельствует о большей эмоциональности, эгоцентричности, полезависимости, подверженности стрессам и меньшей устойчивости выбранных программ поведения.

Обсуждение. Данные исследования позволяют говорить о более высоких показателях развития вербального интеллекта, эмоциональной устойчивости, доминантности и самоконтроля, поленезависимости, способности к прогнозированию (антиципации), общей интернальности и способности к само- организации (процессов целеобразования), что имеет отношение к волевым функциям и произвольной регуляции человека. Данные могут быть использованы при проведении дифференциальной диагностики, а также в целях профотбора и профориентации.

Сегодня на кафедре психологии РГУФКСМиТ, продолжая традиции П.А. Рудика, проводятся дальнейшие исследования волевых (регуляторных процессов) у спортсменов с позиций современной психофизиологии [2-10; 12-15]. Получены новые данные, которые свидетельствуют о наличии индивидуальных особенностей волевой регуляции человека, связанных с особенностями его функциональных асимметрий. Выявлены индивидуальные особенности склонности к риску и импульсивности на примере студентов спортивного вуза [6] с разными признаками доминирования регулятивного блока мозга по А.Р. Лурия [1]. Исследованы и выявлены индивидуальные особенности контроля за действием, обусловленные функциональными асимметриями [7]. Полученные данные могут быть полезны при подготовке спортсменов высокой квалификации (с учетом индивидуальных особенностей произвольной регуляции и контроля за действием в спортивной психологии). Разработаны и апробированы методики психологической и психо-физиологической диагностики регуляторных процессов в спорте, изданы методические рекомендации, рассматривающие вопросы связи функциональных асимметрий человека с его регуляторными (волевыми) характеристиками применительно к спортивной деятельности. Приведены результаты апробации психологических и психофизиологических методик диагностики индивидуальных особенностей регуляторных процессов на выборках студентов спортивного вуза и высококвалифицированных спортсменов [3-10; 12-15;].

Выводы. Анализируя междисциплинарную проблему функциональных асимметрий в спорте, можно отметить, что сегодня происходит становление и развитие нового прикладного направления - спортивной психофизиологии. Это направление имеет собственный предмет изучения, общие и специфические понятия, методологические основы, условия и средства педагогического обеспечения системы физического воспитания и спортивной тренировки с учетом функциональных асимметрий мозга, психофизиологических, 
социально-психологических характеристик спортсменов и на этой основе - последующее дифференцированное обучение с учетом индивидуальных особенностей функциональной специализации и взаимодействия зон мозга.
Исследование выполнено при финансовой поддержке РГНФ, проект №16-06-50146-а (ф): «Комплексное исследование индивидуальных особенностей регуляторных процессов человека в норме и патологии (онтогенетические и психофизиологические аспекты)».

\section{Литература.}

1. Лурия А.Р. Высшие корковые функции человека и их нарушения при локальных поражениях мозга (2-е изд.). - М.: Изд-во МГУ, 1969. - 504 с.

2. Москвин В.А., Москвина Н.В. Межполушарные асимметрии и индивидуальные различия человека. - М.: Смысл, 2011. - 367 С.

3. Москвин В.А., Москвина Н.В. Методика диагностики регуляторных процессов в спорте // Спортивный психолог. -2012.- № 3 (27). - С. 65-66.

4. Москвин В.А., Москвина Н.В. Психофизиология индивидуальных различий в спорте. - М.: НИИ спорта РГУФКСМиТ, 2013. - 128 с.

5. Москвин В.А., Москвина Н.В. Психофизиология индивидуальных различий в спорте высших достижений // Спортивный психолог.- 2011. - № 1 (22). - С. 72-76.

6. Москвин В.А., Москвина Н.В., Шумова Н.С., Ковалевский А.Г. Индивидуальные особенности склонности к риску и импульсивности (на примере студентов спортивного вуза) // Теория и практика физической культуры. - 2012. - № 5. - С. 6-11.

7. Москвин В.А., Москвина Н.В., Шумова Н.С., Ковалевский А.Г. Индивидуальные особенности контроля за действием в спорте // Теория и практика физической культуры. - 2013. - № 1. - С. 76-79.

8. Москвин В.А., Москвина Н.В., Шумова Н.С., Ковалевский А.Г. Взгляды П.А. Рудика на проблему волевой регуляции в спорте // Спортивный психолог. - 2013. - № 2 (29). - С. 15-19.

9. Москвин В.А., Москвина Н.В., Ковалевский А.Г., Шумова Н.С. Психологическая и психофизиологическая диагностика регуляторных процессов в спорте: Методические рекомендации. - М.: НИИ спорта РГУФКСМит, 2013. - 63 с.

10. Москвина Н.В. Мозг, индивидуальные различия и произвольная регуляция человека. - М.: РГУФКСМиТ, 2015. - 150 C.

11. Небылицин В.Д. Психофизиологические исследования индивидуальных различий. - М.: Наука, 1976.336 c.

12. Moskvin V.A., Moskvina N. V. Psychophysiology and features volitional regulation sport university students // European Journal of Education and Applied Psychology. - 2015. - № 3. - P. 62-65.

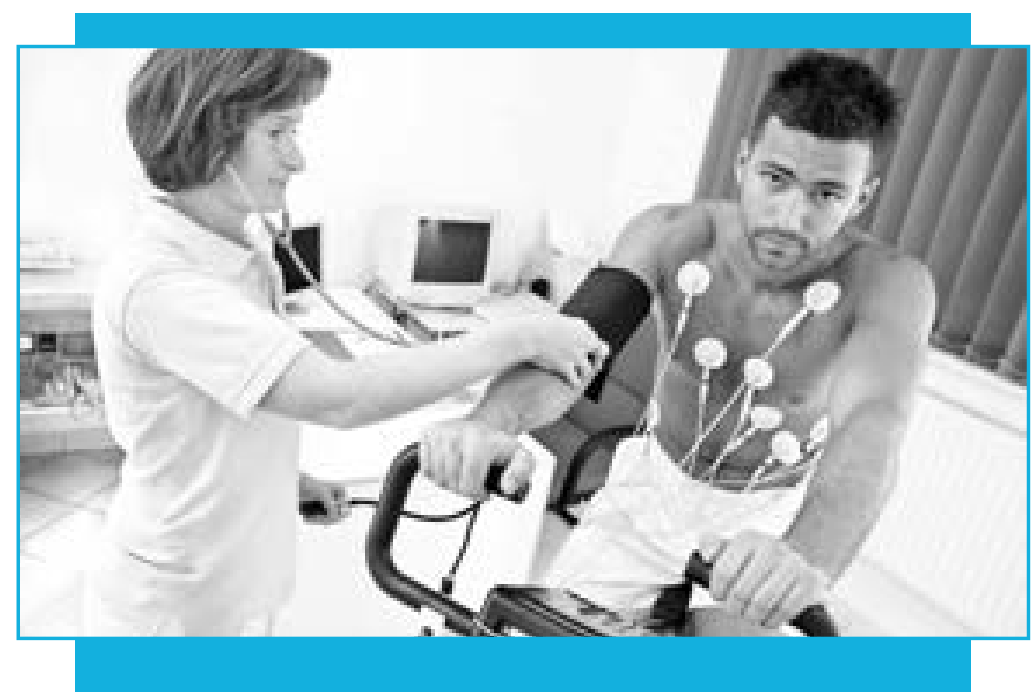

